\title{
DADOS DO CENSO DEMOGRÁFICO E A AVALIAÇÃO DA EVOLUÇÃO DA SEGREGAÇÃO RESIDENCIAL URBANA
}

\author{
Ligia Vizeu Barrozo; William Cabral-Miranda; Natalia Bianchi Galvão
}

Universidade de São Paulo - USP

\section{Resumo}

O objetivo do presente trabalho foi ilustrar como a segregação residencial urbana pode ser avaliada e monitorada a partir de dados do questionário da amostra por área de ponderação dos Censos Demográficos do Instituto Brasileiro de Geografia e Estatística (IBGE) de 2000 e 2010. Entre os dois Censos, embora na média do município a segregação não tenha tido aumento muito importante, localmente as variações foram relevantes, provavelmente associadas à valorização do uso do solo urbano neste período. Os índices utilizados mostram potencial como instrumentos para avaliação da segregação em seus diversos aspectos para subsidiar medidas de redução ou mitigação de suas externalidades.

Palavras-chave: segregação residencial, Índice de Concentração nos Extremos, Censo Demográfico.

\begin{abstract}
Resumen
El objetivo de este trabajo fue ilustrar cómo se puede evaluar y monitorear la segregación residencial urbana a partir de los datos del cuestionario de muestra por área de ponderación del Censo Demográfico del Instituto Brasileño de Geografía y Estadística (IBGE) de 2000 a 2010. Entre los dos El censo, aunque en el municipio la segregación promedio no tuvo mucho aumento, localmente las variaciones fueron relevantes, probablemente asociadas con la valorización del uso del suelo urbano en este período. Los índices utilizados muestran potencial como instrumentos para evaluar la segregación en sus diversos aspectos para subsidiar medidas para reducir o mitigar sus externalidades..
\end{abstract}

Palabras clave: Segregación residencial, Índice de Concentración en los Extremos, censo demográfico.

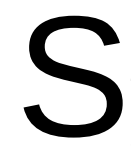

egregação residencial é um conceito amplo que se refere à habitação separada de diferentes grupos populacionais em diferentes partes de uma cidade (GRZEGORCZYK; JACZEWSKA, 2015). Os grupos sociais segregados apresentam relativa homogeneidade interna e heterogeneidade externa quando comparados a grupos do seu entorno (BICHIR, 2009). Para uma vertente teórica, a segregação social e territorial que compreende áreas de informalidade e de pobreza nas cidades da América Latina "não são subprodutos ocasionais de um processo de enriquecimento universal da sociedade urbana, mas mecanismos ativos na diferenciação espacial do território urbano" (SANTOS et al., 2017, p.438) necessários para a reprodução social do capitalismo por meio da forma urbana (CALDEIRA, 1997). Para outros, a segregação residencial apresenta também um aspecto positivo, o da formação da identidade social (SABATINI, 2006). Neste contexto, a confiança é o capital social que conduz à busca pela proximidade entre as pessoas que compartilham de mesmas identidades culturais. Por outro lado, se este processo de assimilação gerar limitações nas opções de interação física entre classes sociais, seus efeitos são negativos, o que tem sido observado na homogeneidade socioespacial nos grupos mais pobres 
das cidades latino-americanas (SABATINI, 2006). As externalidades em áreas de bairros pobres e homogêneos costumam incluir baixo desempenho escolar, desemprego, gravidez na adolescência e maior vulnerabilidade para problemas de dependência de drogas e delinquência, como observado em cidades chilenas por Sabatini et al. (2001 apud SABATINI, 2006). A segregação residencial também pode afetar a saúde das pessoas. O mecanismo seria a intensificação de efeitos psicossociais que envolvem insegurança, ansiedade, isolamento social, ambientes socialmente perigosos, bullying e depressão (MARMOT, 2001).

O tema da segregação residencial urbana tem sido estudado desde os anos 1920 pela Escola de Chicago, nos Estados Unidos e, a partir de 1940, começam a surgir indicadores quantitativos para as análises empíricas (APPARICIO, 2000). Os indicadores ditos espaciais surgem a partir de 1980, permitindo qualificar as divisões dos espaços metropolitanos entre os diferentes grupos. A complexidade conceitual inerente à segregação residencial leva à elaboração de inúmeros indicadores e à necessidade de uma classificação segundo as principais dimensões que abrangem. Assim, segundo Massey e Denton (1988), uma população pode ser segregada de diversas formas, em cinco dimensões: 1- desigualdade se refere à distribuição desigual da população nas unidades geográficas; 2- exposição se refere à probabilidade de contato com representantes de outros grupos (índice de interação) ou do próprio grupo (índice de isolamento); 3- concentração se refere ao espaço físico relativo habitado por um grupo de pessoas; 4- centralização se refere a uma específica variação de concentração (define o nível de habitação próximo ao centro da cidade); 5- agrupamento se refere à proximidade de unidades geográficas habitadas por um dado grupo populacional. Para facilitar a análise da segregação residencial em estudos urbanos, Apparicio et al. (2014) desenvolveram um programa computacional que calcula até 43 indicadores.

A despeito da grande diversidade de indicadores e da relativa facilidade de seus cálculos, o Índice de Concentração nos Extremos (ICE), como uma medida de polarização socioespacial, quantifica os extremos dos grupos privilegiados e com privação em uma métrica única e avalia a extensão da concentração da população em um ou outro grupo (MASSEY, 1996, 2001, 2012). Devido ao reconhecimento de que a segregação residencial pode estar relacionada com as iniquidades em saúde, os ICEs têm sido utilizados, demonstrando associações importantes com hipertensão (FELDMAN et al., 2015), exposição à poluição do ar (KRIEGER et al., 2015), latrocínios e assaltos (KRIEGER et al., 2017), nascimentos prematuros (HUYNH et al., 2017) e mortalidade infantil (HUYNH et al., 2017; BARROZO, 2018). Interessa-nos aqui exatamente as externalidades geradas pela segregação residencial. Compreender as associações que estabelece com a qualidade de vida das pessoas (no seu aspecto empiricamente mais forte - nas condições de saúde e desigualdades nas taxas de mortalidade) - pode contribuir para embasar políticas que promovam a redução da segregação residencial negativa e para o questionamento da representatividade política das minorias desfavorecidas socialmente na esfera local (KRIEGER et al., 2017). Assim, o objetivo do presente trabalho foi ilustrar a utilização dos ICEs para a identificação de segregação residencial e seu monitoramento ao longo do tempo, em escala intraurbana, a partir de dados dos Censos Demográficos do Instituto Brasileiro de Geografia e Estatística (IBGE). Para tal, estudamos a materialização da segregação residencial no município de São Paulo e suas mudanças a partir dos dados dos questionários das áreas de ponderação dos Censos de 2000 e 2010. O município de São Paulo foi escolhido por ser a cidade brasileira mais influente no cenário global, por seu caráter cosmopolita - já que, segundo dados de 2016, possui moradores nativos de mais de 
196 países - e por ser a mais populosa do hemisfério sul. Sua reconhecida desigualdade socioespacial é representativa do produto do mecanismo de urbanização contemporânea das outras megacidades latino-americanas.

\section{O Índice de Concentração nos Extremos}

O ICE é calculado da seguinte forma, segundo a proposta de Massey ${ }^{1}$ (2001 apud KRIEGER et al., 2015):

$\operatorname{ICE} E_{i}=\frac{\left(A_{i}-P_{i}\right)}{T_{i}}$

Ai: número de pessoas categorizadas como pertencendo ao extremo mais privilegiado;

$P i$ número de pessoas categorizadas como pertencentes ao grupo menos privilegiado;

Ti: total da população na área estudada.

O ICE varia de $-1 \mathrm{a}+1$, sendo o valor zero a indicação de ausência de segregação e os valores -1 ou +1 , a maior polarização no extremo inferior ou superior. Diferente do índice de Gini, utilizado para indicar desigualdade econômica, o ICE indica a direção da segregação (valores negativos e positivos) (HUYNH et al., 2017). Além disso, o ICE permite a comparação em escalas e níveis geográficos diferentes.

O primeiro passo para o cálculo do ICE consiste na definição de quais serão considerados os grupos hegemônicos e os grupos em desvantagem social, que variam de acordo com a composição populacional em termos de raça ou cor, renda e educação. A partir da composição da população segundo cor ou raça autodeclarada no Censos do município de São Paulo e dos referenciais históricos, definimos como grupo mais privilegiado as pessoas autodeclaradas brancas e os grupos em desvantagem, as pessoas autodeclaradas pretas, pardas ou indígenas. Foram calculadas quatro diferentes medidas de ICE para os Censos Demográficos de 2000 e 2010, na unidade de área de ponderação: (1) ICE para renda, para o qual foram estabelecidos os percentis 20 e 80 do rendimento; (2) ICE para raça, estabelecendo como extremos o número de pessoas autodeclaradas da cor ou raça branca e o número de pessoas autodeclaradas da cor ou raça preta, parda ou indígena; (3) ICE para educação, estabelecendo como extremos o número de pessoas acima de 25 anos com nível de educação superior e o número de pessoas acima de 25 anos com nível de educação fundamental ou fundamental incompleto; (4) ICE para renda e cor ou raça, estabelecendo como extremos o número de pessoas autodeclaradas da cor ou raça branca cujo rendimento era igual ou superior ao percentil 80 e o número de pessoas autodeclaradas da cor ou raça preta, parda ou indígena cujo rendimento era igual ou inferior ao percentil 20.

\footnotetext{
${ }^{1}$ MASSEY, D. S. The prodigal paradigm returns: ecology comes back to Sociology. In: BOOTH, A.; CROUTERS, A. (Ed.). Does it take a village? Community effects on children, adolescents, and families. New Jersey: Lawrance Erlbaum Associates, 2001. p. 41-48.
} 
A partir de tais definições, os questionários da amostra dos dois Censos foram abertos para a extração e cálculo dos ICEs. A combinação de renda e cor ou raça traz um ganho adicional à análise, uma vez que pode contribuir para indicar se há desvantagem maior quando essas dimensões são vistas de forma combinada. Essa possibilidade só existe porque os questionários da amostra permitem a extração dos dados de um mesmo indivíduo.

Esta pesquisa foi feita a partir da implementação de um projeto em Sistema de Informações Geográficas (ArcGIS 10.1) e da utilização das bases cartográficas das áreas de ponderação dos Censos de 2000 e 2010 e seus respectivos questionários da amostra. Para que fosse possível a comparação dos ICEs entre os dois Censos, as áreas de ponderação foram compatibilizadas para a base cartográfica mais nova, de 2010. Os centroides das áreas de ponderação de 2000 foram interceptados pelos polígonos das áreas de ponderação de 2010. Desta forma, foi possível calcular os ICEs de 2000 segundo agrupamentos das áreas de ponderação de 2010. Os questionários dos dois Censos foram abertos no programa SPSS 20, por meio do qual foram extraídos os dados e calculados os ICEs. Os resultados foram representados cartograficamente para os dois momentos estudados. Para facilitar a interpretação dos resultados que variam de -1 a +1 , os valores absolutos foram classificados em quatro classes: segregação baixa (de 0 a 25), média (de 0,26 a 0,50 ), alta $(0,51$ a 0,75$)$ e muito alta (de 0,76 a 1). Os mapas dos diferenciais entre os Censos mostram as áreas onde houve aumento, diminuição ou não mostraram alteração.

\section{A polarização social em São Paulo}

De acordo com o Censo de 2010, a população do município de São Paulo se autodeclara por raça ou cor segundo a seguinte composição: $60,6 \%$ branca, 30,5\% parda, 6,5 preta, 2,2\% amarela e $0,1 \%$ indígena. Se considerarmos os grupos de raça preta, parda e indígena (PPI), o percentual atinge 37,2. Quanto à educação, $45,4 \%$ da população não tem ensino fundamental completo, $23,5 \%$ tem ensino médio, $15,9 \%$ tem ensino fundamental completo e $15,2 \%$ tem ensino superior completo. Em outras palavras, $61,3 \%$ da população tem nível fundamental incompleto ou completo e $38,7 \%$ tem escolaridade a partir do nível médio.

Embora a segregação de cor ou raça não aconteça de forma independente de suas características associadas como renda, escolaridade e cultura, o estudo da segregação racial, de renda e de educação pode contribuir para a compreensão da configuração do espaço urbano em seus múltiplos aspectos. Os mapas das Figuras 1 a 4 apresentam os quatro tipos de segregação estudados.

Dos quatro tipos, na média, a segregação por cor ou raça diminuiu de forma generalizada no município, com exceção da região sul onde teve aumento, de 2000 para 2010 (Figura 1). Este fenômeno precisa de uma análise mais detalhada das mudanças da autodeclaração de cor ou raça no período, já que pode indicar resultado de maior consciência racial em função de movimentos de conscientização e não maior inclusão por mudança de endereço a partir da melhora de status social. 


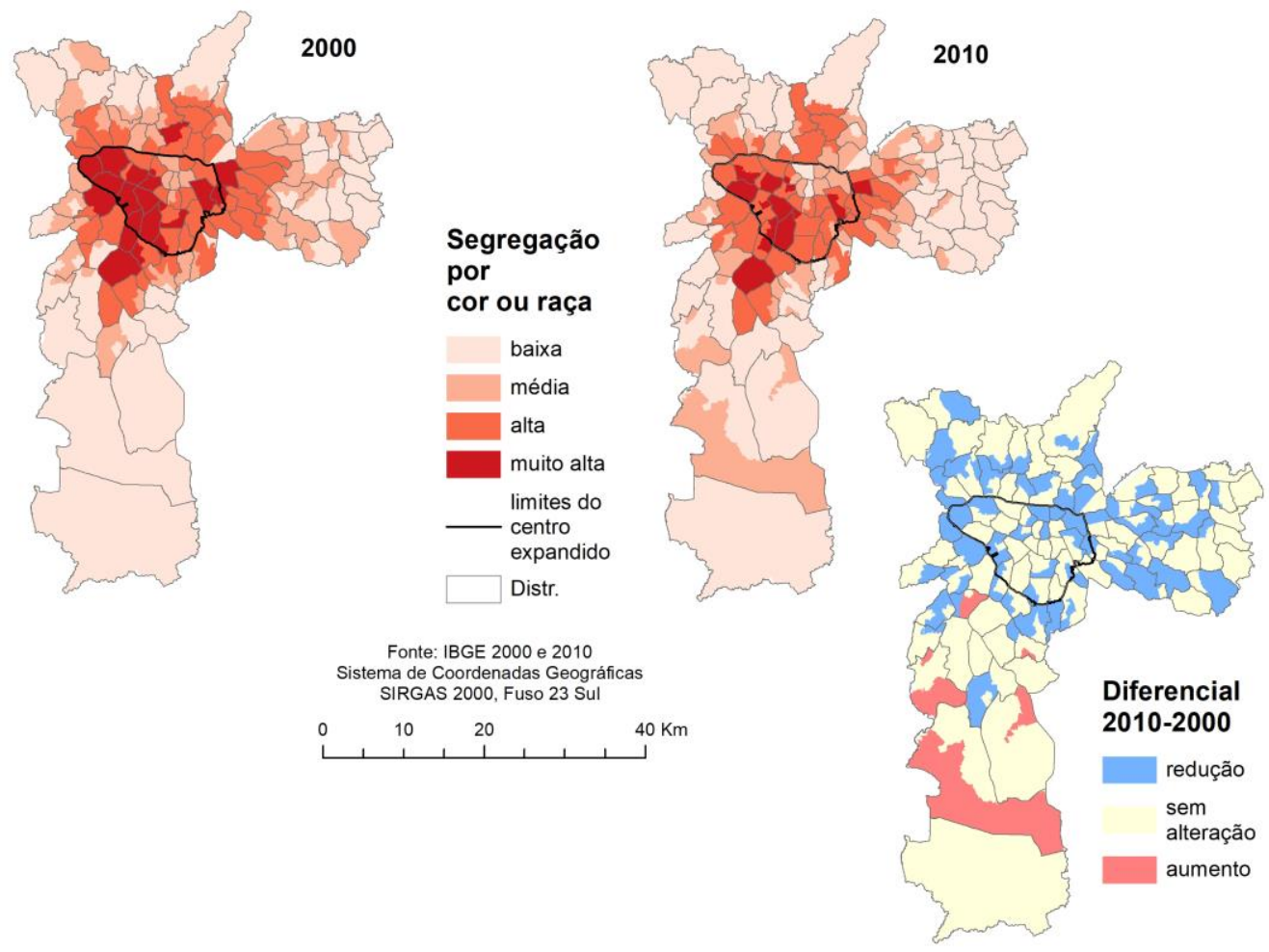

Figura 1. Segregação por cor ou raça, de acordo com o Índice de Concentração nos Extremos agrupado em classes, para os Censos de 2000 e 2010 e o diferencial da segregação entre os dois Censos. 
A segregação por educação, por sua vez, mostra aumento negativamente nas periferias e na porção central do município e teve redução no quadrante sudoeste (Figura 2). Houve aumento da concentração de população sem instrução ou ensino fundamental incompleto em relação à população com ensino superior nas periferias.

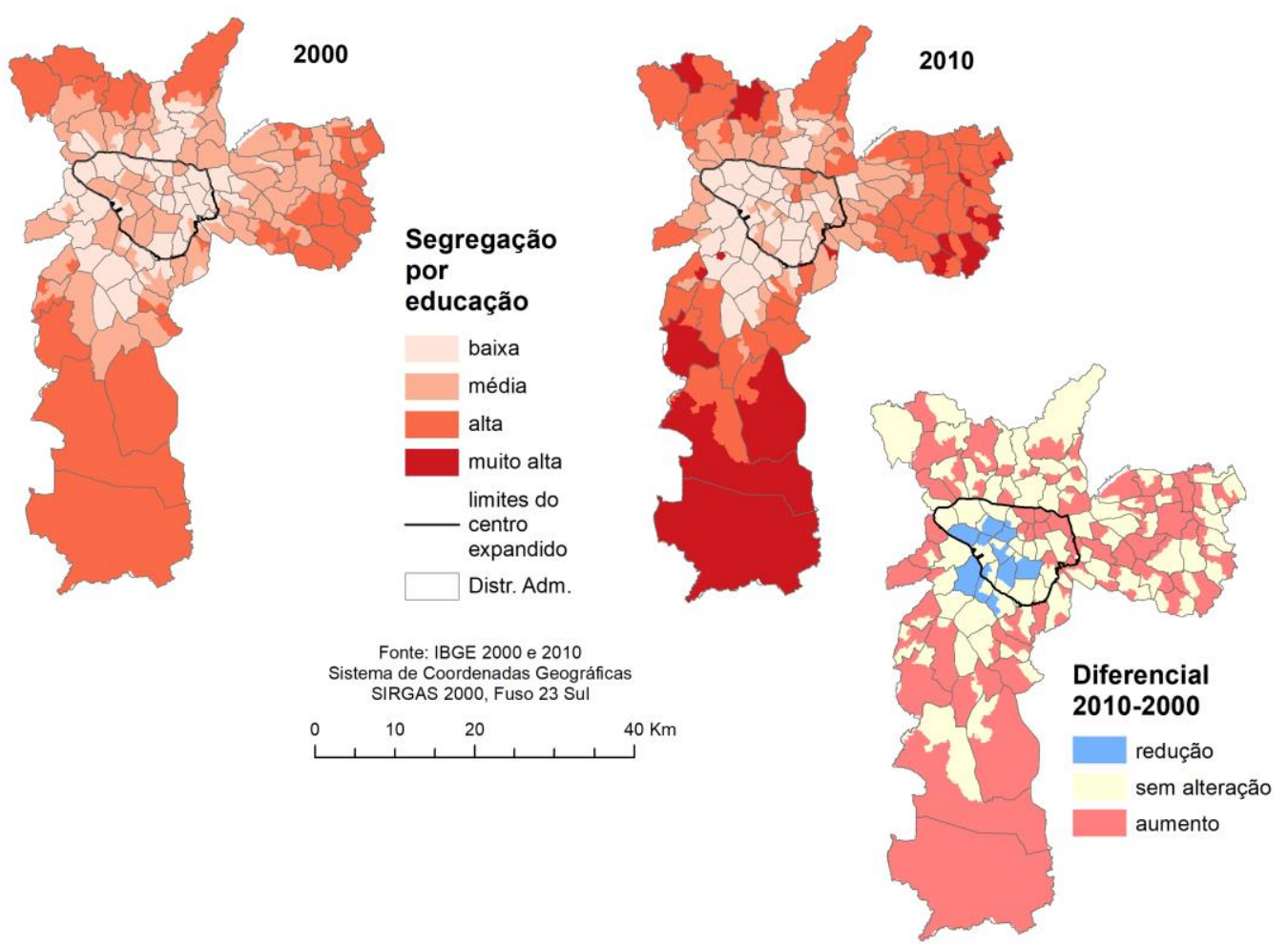

Figura 2. Segregação por educação, de acordo com o Índice de Concentração nos Extremos agrupado em classes, para os Censos de 2000 e 2010 e o diferencial da segregação entre os dois Censos. 
A segregação por renda teve acréscimo em áreas contíguas importantes do município, chegando a atingir Distritos Administrativos inteiros na zonal Sul (Vila Mariana, Santo Amaro e Socorro e) e na zona Oeste (Alto de Pinheiros e Itaim Bibi) (Figura 3). Na porção central, nos Distritos do Bom Retiro e Brás, houve inversão de segregação, pois havia predomínio da população do percentil 80 sobre a do percentil 20 no ano 2000 (que só é possível observar nos dados quantitativos, não mostrados), evidenciando um empobrecimento destes

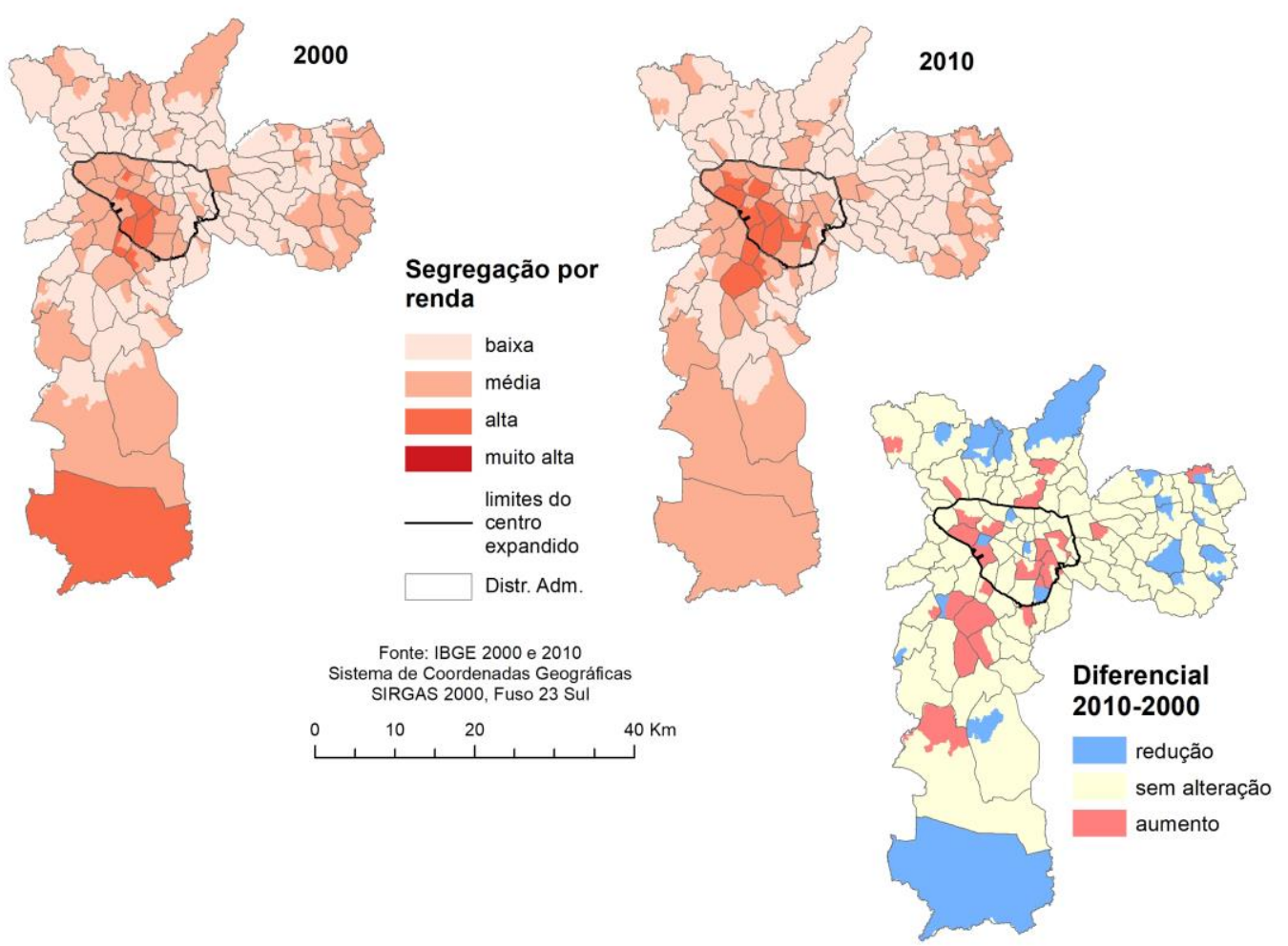

Figura 3. Segregação por renda, de acordo com o Índice de Concentração nos Extremos agrupado em classes, para os Censos de 2000 e 2010 e o diferencial da segregação entre os dois Censos. 
A segregação por renda associada com a cor ou raça tem espalhamento espacial menor do que se considerada apenas a renda. No período houve aumento da exclusão em algumas áreas de ponderação principalmente dentro do centro expandido, mas também no sul do Itaim Bibi (zona Oeste), em toda área dos Distritos de Santo Amaro e Socorro (zona Sul) (Figura 4).

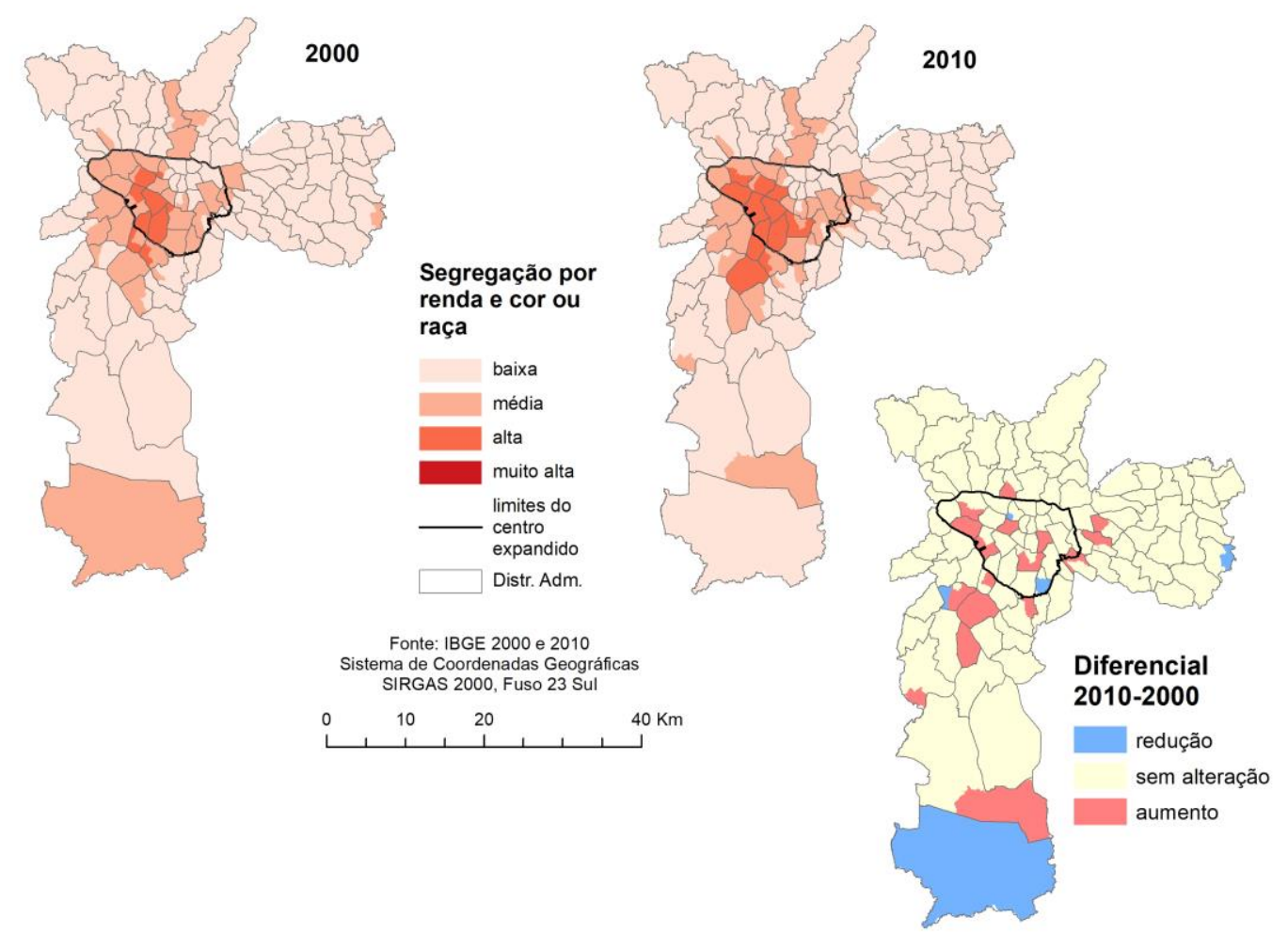

Figura 4. Segregação por renda combinada com a cor ou raça, de acordo com o Índice de Concentração nos Extremos agrupado em classes, para os Censos de 2000 e 2010 e o diferencial da segrega-ção entre os dois Censos. 
A segregação urbana na Europa e nos Estados Unidos da América é mais associada com grupos raciais, etnias ou religião enquanto nas cidades da América Latina o enfoque se dá nos aspectos socioeconômicos (GREENSTEIN; SABATINI; SMOLKA, 2000). Mais recentemente a segregação em três Regiões Metropolitanas europeias foi estudada do ponto de vista do nível de escolaridade (GRZEGORCZYK; JACZEWSKA, 2015). Tanto a Região Metropolitana de Paris, quanto as de Varsóvia e Berlim mostraram ocorrer a maior segregação em grupos de status social extremo de alta escolaridade. Nos três casos, a maior segregação ocorre em relação à metrópole como um todo, com relativa homogeneidade das cidades capitais. Estas se tornaram mais elitizadas, sendo Paris a de mais alta segregação dos grupos de status social mais elevado, que habitam os enclaves do oeste (os chamados "distritos bonitos"). Varsóvia apresenta a concentração da elite principalmente na cidade capital e ao mesmo tempo, a maior segregação em grupos com o status mais baixo. Berlim apresenta padrões de segregação diferentes entre oeste e leste da cidade. A parte oeste apresenta a concentração de pessoas com baixa escolaridade.

Nos Estados Unidos da América, a literatura sobre a segregação racial é ampla e diversa, sendo raros os estudos sobre a segregação por renda. Uma das contribuições neste tema é de Watson (2009) que estudou a segregação econômica das áreas metropolitanas norte-americanas encontrando uma forte e robusta relação entre desigualdade de renda e segregação por renda. A segregação ocorreria porque as pessoas mais ricas teriam mais condições de escolher bairros melhores, já que a escolha do local de residência tem implicação direta no tempo gasto para deslocamentos e na alocação de bens públicos. A segregação, por sua vez, afetaria o lugar. Por exemplo, a baixa renda pode gerar o aumento da criminalidade em bairros de baixa qualidade, o que, por sua vez, afetaria os preços relativos dos bairros de baixa e alta criminalidade. Analogamente, famílias mais ricas podem produzir externalidades de bairro mais positivas (investindo em paisagismo ou bens públicos locais, por exemplo). Nesse caso, os bairros tornar-se-iam mais desejáveis e o preço relativo dos altos rendimentos aumentaria à medida que os ricos se tornassem mais ricos. Esses efeitos indiretos poderiam resultar em um vínculo adicional entre desigualdade e segregação.

A segregação residencial das cidades brasileiras vem sendo estudada por autores da geografia, sociologia e entre pesquisadores da área de planejamento urbano, para a compreensão dos processos responsáveis (CALDEIRA, 1996; CARLOS, 2003; LENCIONI, 2008; VILLAÇA, 2011, entre outros). A segregação residencial atua de forma muito negativa no município de São Paulo. A violência relacionada à segregação nesta e em outras cidades capitais de Regiões Metropolitanas brasileiras tem levado a uma situação generalizada de insegurança e a efeitos psicossociais a toda população. Estudo recente mostrou que a segregação residencial está associada à mortalidade infantil, aquela que ocorre em crianças de até um ano de idade (BARROZO, 2018). Entre indicadores como renda, índice de Gini, um índice socioeconômico composto e os Índices de Concentração nos Extremos estudados, o modelo com o ICE por renda e cor ou raça foi o que apresentou melhor ajuste, evidenciando a necessidade de se olhar a segregação econômicoracial de forma conjunta para a melhor compreensão das desigualdades em saúde. Em São Paulo, estudar apenas a renda ou a educação de forma isolada contribuem menos do que indicadores de segregação de forma combinada. 
Estudando a pobreza urbana, a segregação e as redes sociais em São Paulo e Salvador, Marques (2015) observou a quase completa ausência de pessoas não-pobres nas redes sociais de indivíduos pobres e que as redes sociais destes costumam ser menores e menos variadas em termos de sociabilidade do que as redes de pessoas de classe média. A segregação residencial implica em redução no acesso a serviços públicos ligados ao bem-estar (BICHIR, 2009; MARQUES, 2015), a oportunidades de emprego (WATSON, 2009) e a inovações tecnológicas que podem ser importantes para a saúde (WEISS; EIKEMO, 2017) e o desenvolvimento de um indivíduo.

O presente estudo pretende apenas trazer o ICE como variável operacional para estudos de segregação a partir dos dados censitários, já que as variações deste índice mostram diversos aspectos deste processo. Além de permitir o monitoramento da evolução da segregação, como neste estudo, é possível utilizar o ICE para verificar se instrumentos para promoção de inclusão socioespacial tal como o que tem sido aplicado no município de São Paulo - a Outorga Onerosa do Direito de Construir - tem conseguido mitigar as condições de vulnerabilidade social (LEITE et al., no prelo). 
Referências

APPARICIO, P. Les indices de ségrégation résidentielle: un outil intégré dans un système d'information géographique. Cybergeo, 16 jun. 2000. Disponível em: $<$ http://cybergeo.revues.org/12063>.

APPARICIO, P.; MARTORI, J. C.; PEARSON, A. L.; FOURNIER, É.; APPARICIO, D. An OpenSource Software for Calculating Indices of Urban Residential Segregation. Social Science Computer Review, v. 32, n. 1, p. 117-128, 7 fev. 2014. Disponível em: <http://journals.sagepub.com/doi/10.1177/0894439313504539>.

BARROZO, L. V. Desigualdades na mortalidade infantil no Município de São Paulo: em busca do melhor indicador. Confins, n. 37, 24 set. 2018. Disponível em: $<$ http://journals.openedition.org/confins/15010>.

BICHIR, R. M. Determinantes do acesso à infra-estrutura urbana no município de São Paulo. Revista Brasileira de Ciências Sociais, v. 24, n. 70, p. 75-89, 2009.

CALDEIRA, T. Building up walls: the new pattern of spatial segregation in São Paulo. International Social Sciences Journal, v. 48, n. 147, 1996.

CALDEIRA, T. P. R. Enclaves fortificados: a nova segregação urbana. Novos Estudos-CEBRAP, v. 47, p. 155-176, 1997.

CARLOS, A. F. A. São Paulo: dinâmica urbana e metropolização. Revista Território, Rio de Janeiro, v. Ano VII, n. set./out., p. 77-89, 2003.

FELDMAN, J. M.; WATERMAN, P. D.; COULL, B. A.; KRIEGER, N. Spatial social polarisation: using the Index of Concentration at the Extremes jointly for income and race/ethnicity to analyse risk of hypertension. Journal of Epidemiology and Community Health, v. 69, n. 12, p. 1199-1207, dez. 2015. Disponível em: <http://jech.bmj.com/lookup/doi/10.1136/jech-2015205728>.

GREENSTEIN, R.; SABATINI, F.; SMOLKA, M. Urban spatial segregation: forces, consequences and policy responses. Land Lines, p. 7-9, 2000.

GRZEGORCZYK, A.; JACZEWSKA, B. Measures of social segregation in the context of Warsaw, Berlin and Paris metropolitan areas. Miscellanea Geographica, v. 19, n. 3, 1 jan. 2015. Disponível em: <https://www.degruyter.com/view/j/mgrsd.2015.19.issue-3/mgrsd-20150012/mgrsd-2015-0012.xml>.

HUYNH, M.; SPASOJEVIC, J.; LI, W.; MADURO, G.; VAN WYE, G.; WATERMAN, P. D.; KRIEGER, N. Spatial social polarization and birth outcomes: preterm birth and infant mortality - New York City, 2010-14. Scandinavian Journal of Public Health, p. 1-10, 6 abr. 2017. Disponível em: <http://journals.sagepub.com/doi/10.1177/1403494817701566>.

KRIEGER, N.; FELDMAN, J. M.; WATERMAN, P. D.; CHEN, J. T.; COULL, B. A.; HEMENWAY, D. Local Residential Segregation Matters: Stronger Association of Census Tract Compared to Conventional City-Level Measures with Fatal and Non-Fatal Assaults (Total and Firearm Related), Using the Index of Concentration at the Extremes (ICE) for Racial, Econ. Journal of 
Urban Health, v. 94, n. 2, p. 244-258, 27 abr. 2017. Disponível em: <http://link.springer.com/10.1007/s11524-016-0116-z>.

KRIEGER, N.; WATERMAN, P. D.; GRYPARIS, A.; COULL, B. A. Black carbon exposure, socioeconomic and racial/ethnic spatial polarization, and the Index of Concentration at the Extremes (ICE). Health \& Place, v. 34, p. 215-228, jul. 2015. Disponível em: <http://linkinghub.elsevier.com/retrieve/pii/S135382921500074X>.

LEITE, C.; ACOSTA, C.; HERLING, T.; BARROZO, L.; SALDIVA, P. Indicadores Científicos para o Uso de Financiamento Urbano na Diminuição de Desigualdades Sociais e em Saúde. Revista Estudos Avançados, v. no prelo, [s.d.]

LENCIONI, S. Concentração e centralização das atividades urbanas: uma perspectiva multiescalar. Reflexões a partir do caso de São Paulo. Revista de geografía Norte Grande, n. 39, maio 2008. Disponível em: <http://www.scielo.cl/scielo.php?script=sci_arttext\&pid=S0718$34022008000100002 \& \operatorname{lng}=e n \& n r m=i s o \& t \operatorname{lng}=e n>$.

MARMOT, M. Psychosocial and material pathways in the relation between income and health: a response to Lynch et al. BMJ, v. 322, n. 7296, p. 1233-1236, 19 maio 2001. Disponível em: <http://www.bmj.com/cgi/doi/10.1136/bmj.322.7296.1233>.

MARQUES, E. Urban Poverty, Segregation and Social Networks in São Paulo and Salvador, Brazil. International Journal of Urban and Regional Research, v. 39, n. 6, p. 1067-1083, nov. 2015. Disponível em: <http://doi.wiley.com/10.1111/1468-2427.12300>.

MASSEY, D. S. The age of extremes: concentrated affluence and poverty in the twenty-first century. Demography, v. 33, p. 395-412, 1996.

MASSEY, D. S. Reflections on the dimensions of segregation. Social Forces, v. 91, p. 39-43, 2012.

MASSEY, D. S.; DENTON, N. A. The Dimensions of Residential Segregation. Social Forces, v. 67, n. 2, p. 281-315, 1 dez. 1988. Disponível em: <https://academic.oup.com/sf/articlelookup/doi/10.1093/sf/67.2.281>.

SABATINI, F. The Social Spatial Segregation in the Cities of Latin America. [s.l: s.n.].

SANTOS, A. P.; POLIDORI, M. C.; PERES, O. M.; SARAIVA, M. V. O lugar dos pobres nas cidades: exploração teórica sobre periferização e pobreza na produção do espaço urbano Latino-Americano. urbe. Revista Brasileira de Gestão Urbana (Brazilian Journal of Urban Management), v. 9, n. 3, p. 430-442, 2017.

VILLAÇA, F. São Paulo: urban segregation and inequality. Estudos Avançados, v. 25, n. 71, p. 37-58, 2011.

WATSON, T. Inequality and the measurement of residential segregation by income in American neighborhoods. Review of Income and Wealth, v. 55, n. 3, p. 820-844, 2009.

WEISS, D.; EIKEMO, T. A. Technological innovations and the rise of social inequalities in health. Scandinavian Journal of Public Health, v. 45, n. 7, p. 714-719, 22 nov. 2017. Disponível em: <http://journals.sagepub.com/doi/10.1177/1403494817711371>. 